\title{
Research on the Development of University Library Regional Alliances in China
}

\author{
Lei Yi \\ Information Quality Institute, Beijing University of Chemical Technology, Beijing, China \\ Email: 81058259@qq.com
}

How to cite this paper: Yi, L. (2020). Research on the Development of University Library Regional Alliances in China. Voice of the Publisher, 6, 122-130.

https://doi.org/10.4236/vp.2020.63014

Received: August 24, 2020

Accepted: September 19, 2020

Published: September 22, 2020

Copyright $\odot 2020$ by author(s) and Scientific Research Publishing Inc. This work is licensed under the Creative Commons Attribution International License (CC BY 4.0).

http://creativecommons.org/licenses/by/4.0/

\begin{abstract}
With the development of China's social economy, higher education and the Internet, China has established a number of regional alliances (RA) of university libraries (UL). The university library regional alliances (ULRAS) are an important part of university library alliances (ULAS). The development of ULRAS in China plays an important role in promoting the construction of ULAS and improving the whole network system of Chinese university library alliances (CULAS). This paper mainly adopts the method of case analysis to study the development of ULRAS in China from the perspectives of development status, characteristics and trend. The purpose is to study the general model of the development of ULAS in China and provide reference for the construction of RA in other regions of China and other countries in the world.
\end{abstract}

\section{Keywords}

University Library Alliances, University Library Regional Alliances, Chinese University Library Alliances

\section{Introduction}

With the vigorous development of China's social and economic, higher education and the Internet, the "co-construction and sharing" (CCS) has become the strong voice of China's UL cooperation. In the past 20 years, the construction of university library alliances (ULAS) in China has made great progress, and large-scale regional alliances (RA) have been established in various provinces. The development of regional library alliances (RLAS) in China has made great contributions to the improvement of the system construction and the promotion of the development of ULAS in China. This paper mainly adopts the method of case analysis to study the RA of UL in China from the status, models and trend, 
so as to provide reference for the construction of regional alliances of UL in other regions of China and other countries in the world.

\section{Development Status}

\subsection{Provincial Regional Alliances}

In the past 20 years, so many ULAS have been established in China, as shown in Table 1 (Yi, 2020). It is not difficult to find that there are three factors that play a key role in the development of regional university library alliances (RULAS) in each province. First of all, the construction and development of RULAS cannot do without the strong support of local governments (Yi, 2014). In the process of the development of the provincial RULAS, the provincial education departments are often the main body of investment and management. For example, the $\mathrm{Hu}$ nan Provincial Department of Education (PDE) included the construction of the Hunan Academic Digital Library (HADL) as a key project in its 2004 work deployment. In April 2004, the project passed the official bidding, and Hunan Normal University was finally determined to be the contractor for the construction of the project (Tan \& Huang, 2019). Without the strong support of the HPDE, HADL would be impossible to be built. Another example is the Hubei University Digital Library (HUDL), which is invested and constructed under the leadership of the Hubei PDE to build a shared service system (SS) for the literature resources (LR) of universities across the province (Cheng \& Pei, 2008). Its purpose is to rely on modern network technology (including big data, artificial intelligence, Internet of things, blockchain, cloud computing, etc.) to use the LR of all UL in the province as a foundation, to establish a document resource (DR) system and an online public SS that combines paper collections and electronic documents to serve teachers and students in colleges and universities across the province.

Table 1. Representatives of regional alliance of provincial UL in China.

\begin{tabular}{|c|c|c|c|}
\hline Alliance name & Management center & $\begin{array}{l}\text { Creation } \\
\text { time }\end{array}$ & $\begin{array}{l}\text { Number of } \\
\text { libraries }\end{array}$ \\
\hline $\begin{array}{c}\text { Jiangsu Academic Library Information } \\
\text { System }\end{array}$ & Nanjing University Library & 1997 & 175 \\
\hline Hunan Academic Digital Library & Hunan Normal University & 2004 & 38 \\
\hline Zhejiang Academic Digital Library & Zhejiang University Library & 2008 & 80 \\
\hline Anhui Academic Digital Library & $\begin{array}{l}\text { Library of University of science } \\
\text { and technology of China }\end{array}$ & 2009 & 104 \\
\hline Fujian University Digital Library & Fuzhou University Library & 2011 & 52 \\
\hline Jiangxi Academic Digital Library & Jiangxi Normal University Library & 2012 & 68 \\
\hline Yunnan University Library Alliance & Yunnan Normal University Library & 2012 & 41 \\
\hline \multicolumn{4}{|l|}{ Sichuan Province Double First-Class } \\
\hline $\begin{array}{l}\text { University Library Construction } \\
\text { Alliance }\end{array}$ & Sichuan University Library & 2017 & 8 \\
\hline
\end{tabular}


Secondly, modern network technology is an indispensable tool for alliances building. The construction of HUDL mainly includes two parts: a DR system and an online public service platform. Its portal application system was officially opened in May 2009. The unified portal software platform of Jiangxi Academic Digital Library (JADL) was officially opened in December 2014. The platform has one-stop resource search, DD, characteristic resource construction, mobile library, paper submission and other functions (Hou et al., 2017).

Thirdly, there is a subjective desire among UL to share resources through alliances construction (AC), which is also an important factor in promoting AC. The Anhui Academic Digital Library (AADL) was officially launched in 2009. It relies on the library of the University of Science and Technology of China as the main library, and takes Anhui University Library (UL), Hefei University of Technology Library, Anhui Medical UL, Anhui Agricultural UL as digital document service centers (Yan, 2009). In December 2012, the launching ceremony of the Yunnan University Library Alliance (YNULA) was held at Yunnan Normal University, the curators from 41 UL including Yunnan Nationalities University, Kunming University of Science and Technology, Yunnan University, and Dali University signed the admission ceremony. As the first university alliance officially launched in Yunnan Province, the establishment of the YNULA is conducive to the joint procurement of information resources (IR) and the establishment of regional libraries, and promotes the construction of characteristic data resource libraries among member libraries in the alliance, and realizes information the expansion of shared space and the CCS of resources (Li \& Duan, 2015). In October 2017, the "Sichuan Province Double First-Class UL Construction Alliance" was announced in the Sichuan UL, whose members include the top 8 universities in Sichuan Province.

\subsection{Municipal Regional Alliances}

From the perspective of the development of RA of Chinese academic libraries, not only large provincial-level alliances have been established, but academic libraries in a city are also very keen to establish alliances, as shown in Table 2. For example, Guangzhou UL Alliance currently has 12 member libraries, and has built digital resource systems such as regional resource platform, joint catalog of foreign periodicals, Free Electronic Full-text Database, innovative reference digest library, journal evaluation and contribution system, online information

Table 2. Representatives of municipal-level RA.

\begin{tabular}{cccc}
\hline Alliance name & Founding time & $\begin{array}{c}\text { Establishment } \\
\text { location }\end{array}$ & $\begin{array}{c}\text { Number of } \\
\text { libraries }\end{array}$ \\
\hline Guangzhou University Library Alliance & 1994 & Guangzhou & 12 \\
Changbei University Library Consortia & 2010 & Nanchang & 8 \\
Nanjing Chengdong University Library Consortia & 2012 & Nanjing & 5 \\
Jiaxing University Library Alliance & 2014 & Jiaxing & 7 \\
\hline
\end{tabular}


literacy education, etc.

In a city, relying on geographic advantages to establish alliances is often an important feature of such alliances. The member libraries of Changbei UL Consortia include Jiangxi University of Finance and Economics Library, East China Jiaotong UL, Jiangxi Agricultural UL, Nanchang Hangkong UL, East China University of Technology Library, etc., which realizes the integration of traditional documents and digital resources of Changbei University's libraries on the same platform, as well as unified scheduling and use, original electronic DD, and interlibrary loan of paper documents, providing readers with a full range of document acquisition services (Yang et al., 2014). In May 2012, five colleges and universities, Nanjing University of Aeronautics and Astronautics, Nanjing University of Science and Technology, Nanjing Agricultural University, Nanjing Forestry University, and Nanjing Institute of Physical Education established the "UL Consortia in the Eastern District of Nanjing". The alliance has further developed a unified resource retrieval and service platform on the basis of the loan and return service, and the readers can not only search the collection resources of the university, the five member libraries of the consortia and the national UL, but also search other UL. The electronic resources, and document resources can be obtained through original text delivery. The members of the Jiaxing UL Alliance include seven UL, including the Jiaxing UL, the Tongxiang Campus Library of Zhejiang Media College, and the Zhejiang College Library of Tongji University. The alliance hopes to vigorously promote the development of the joint construction and sharing of regional university LR and the innovation of information services (IS) models through the in-depth exchanges and cooperation of the libraries of the fraternal colleges and universities, so as to better provide resource guarantee and knowledge for the city's higher education and economic and social development service.

\subsection{Inter-Provincial Regional Alliances}

In April 2011, the Shanghai Municipal Education Commission, the Jiangsu PDE, and the Zhejiang PDE jointly signed the "Framework Agreement for UL Alliance in the Yangtze River Delta", marking the establishment of the "Yangtze River Delta University Library Alliance (YRDULA)". The purpose of the YRDULA is to jointly build a service sharing platform for academic libraries in the Yangtze River Delta region, including print resources, with digital resources as the main body, so as to realize the co-construction, mutual knowledge and sharing of academic literature and IR in the Yangtze River Delta (Zhuang, 2012). In May 2016, the "Beijing-Tianjin-Hebei UL Information Resource Service and Sharing Collaborative Innovation Alliance" was established by the libraries of four universities, including University of Science and Technology Beijing, Beijing Technology and Business University, Tianjin University of Science and Technology, and Hebei University of Science and Technology. In terms of jointly building a collaborative service platform, establishing a joint service team, and 
collaborative service innovation, the Beijing-Tianjin-Hebei DR sharing mechanism will be established. In June 2017, the "Guangdong-Hong Kong-Macao UL Alliance" initiated by the University of Macau Library and seconded by the Chinese University of Hong Kong Library and Sun Yat-sen UL was formally established. The purpose of the alliance is to bring together elite UL in Guangdong, Hong Kong and Macau, promote exchanges and cooperation between libraries in the three places, promote the joint construction and sharing of resources, and achieve the goal of mutual benefit and win-win results.

\section{Development Models}

\subsection{Phased Construction}

In 1997, Jiangsu Academic Library Information System (JALIS) was officially launched. Therefore, Jiangsu Provincial Education Department set up a leading team of JALIS, which is specifically responsible for the organization and implementation of the construction scheme, management coordination, supervision and inspection. JALIS phase I has established a complete SS (regional circulation management system). The "regional circulation management system (MS)" independently developed by JALIS phase II has covered more than 120 universities and scientific research institutes in the province, the $80 \%$ of the universities in the province have joined the JALIS joint catalog system. The total number of books and documents in the collection can exceed 50 million, which has been opened to universities and society in the whole province. It has been implemented in six regional teaching consortia including Nanjing, Changzhou, Huaian, Yancheng, Xuzhou and Nantong At present, it has provided services such as joint catalog query, interlibrary loan and reference consultation, and has carried out DD cooperation with world-famous libraries such as University of Pittsburgh East Asia Library, Australian National Library, Taiwan UL and so on, so as to continuously improve the international level. The third phase of JALIS has carried out the construction of high-quality teaching resources database which is closely related to the reality of Jiangsu higher education, including brand characteristic specialty, excellent course, multimedia teaching courseware, practical teaching, teaching reference resource database, and other database construction closely related to teaching and scientific research $(\mathrm{Wu} \& \mathrm{Zhou}$, 2006).

The digital DR sharing SS of Guangdong colleges and universities was approved in 2005. In the first phase, six digital education and teaching resource centers were established, namely the "medical RC" mainly undertaken by the library of Southern Medical University, the "agricultural and life science RC" mainly undertaken by the library of South China Agricultural University, the "Engineering RC" mainly constructed by the library of Guangdong University of technology, the "foreign linguistics $\mathrm{RC}$ " is mainly constructed by the library of Guangdong University of Foreign Studies, "the RC of economics, management and law" is mainly contracted by the library of Guangdong University of Com- 
merce, and the "RC of Higher Vocational Technology" is constructed by the library of Guangdong Normal University of technology. In 2010, the second phase of the project was launched to construct the "construction project (CP) of digital resource sharing (RS) SS of books and documents of Guangdong colleges and universities". The CP was "Science Resource Center (RC)" mainly undertaken by the library of South China University of technology, and "Agronomy and Life Science RC" mainly undertaken by the library of South China Agricultural University, the "Medical RC" mainly constructed by the library of Southern Medical University, the "Engineering RC" mainly constructed by the library of Guangdong University of technology, and the "foreign linguistics RC" mainly constructed by UL of foreign trade of Guangdong Province, and "traditional Chinese medicine and traditional Chinese Medicine Digital RC" mainly undertaken by Guangzhou University of traditional Chinese medicine library.

The construction of AADL phase I enables the centralized utilization and sharing of the scattered electronic LR of colleges and universities in the province, creates a first-class network environment for teaching and scientific research of colleges and universities in the province, fully meets the teaching and scientific research needs of teachers, students and innovative subjects in Anhui Province, and provides high-efficiency, high-quality and all-round literature for teaching, scientific research and key discipline construction of colleges and universities in Anhui Province. In the second phase of AADL construction, the library of the University of Science and Technology of China is the provincial digital library general library, and the other nine UL are the provincial digital literature service center. In the form of the provincial university digital library alliance, based on the systematic digital academic IR, with the advanced digital library information technology as the means, and relying on the stable Internet, the AADL will gradually take shape. It has become a digital information resource guarantee platform and SS with domestic advanced level, unified planning, resource service sharing, multi-level, complete functions, rich resources, high integration, stable mechanism and efficient operation. Through the construction of Anhui Province Network Course Learning Center, Anhui Province regional higher education open education resources alliance will be established to realize the CCS of high-quality education resources, build personalized personal online learning center, and create a new online education mode to promote the continuous improvement of higher education teaching quality in Anhui Province.

\subsection{Project Operation}

Zhejiang Academic Digital Library (ZADL) adopts a project MS, and the management center of ZADL determines the subprojects to be constructed according to the plan approved by the Zhejiang PDE. The Management Center (MC) of ZADL organizes the application for the establishment of ZADL construction sub-projects every year, and at the same time inspects the construction of the sub-projects in the previous year. On the basis of application, expert review, and 
approval by the PDE, the Zhejiang PDE officially determined the sub-projects to undertake the construction of colleges and universities that year, and allocated construction funding. After the implementation of the ZADL sub-project, the MC of ZADL will be responsible for the process management, performance appraisal, follow-up service and other daily work of the sub-project. ZADL sub-project construction (SPC) universities accept the management and supervision of the $\mathrm{MC}$ of $\mathrm{ZADL}$, and according to the unified deployment of the MC of ZADL, undertake the daily service guarantee work after the completion of the SPC tasks. After the project construction (PC) period is over, the PDE organizes experts to check and accept the ZADL PC, and inspect and assess the use of funds and construction benefits of the CP of universities (Tian \& He, 2017).

In order to effectively ensure the construction progress and quality of the project, the HUDL PC implements a three-level working mechanism of leadership team (LT), management center (MC) and special work team. The LT is the decision-making leadership organization for HUDL construction, and the MC is the functional organization and executive organization for the construction of this project. The MC is located in Wuhan University, under which three professional teams are set up-system team, DR construction team and service team, which are responsible for the organization, coordination and implementation of PC. With the gradual deepening of PC and the development of various special tasks, the MC has set up special working teams under three working teams according to actual needs. Among them, the system team has established a CD-ROM processing team with books. A joint catalog work team has been established under the resource team. The document delivery team and reference consulting team are set up under the service team. In order to be able to give full play to the advantages of disciplines and collections of each university, 18 discipline documentation (DD) centers have been established. The establishment of the DD denter has further improved the resources and SS of HUDL.

\section{Development Trend}

The fourth phase of JALIS mainly relies on university informatization (UI) and big data centers to provide resources and services for the readers, in order to adapt to the development of UI and big data technology, a unified, integrated, distributed, open, multi-level and personalized, "Jiangsu University Digital Library Cloud Service Platform" will be built. HADL has played an innovating and advancing role in the digitization of university LR, and promoted the formation of various types of UL alliance cooperative organizations, which is not only a working entity, but also an academic research institution and business training institution. In addition to studying the operating mechanism and development of digital libraries, they should also engage in the research of IS and digital library environments. HADL is not only an information or knowledge warehouse, but also an information and knowledge discovery and learning system. The service of "Fujian University Digital Library" (FULink) has been transformed from 
the original four major contents of "Document Provision", "Joint borrowing", "Mobile FULink", and "CD with Books" to the vast number of teachers and students throughout the province "Knowledge Center", "Learning Center" and "Communication Center". AADL will eventually be built into an information consulting center, a knowledge innovation and dissemination center, an online course teaching center, and a social service center that provide IS for all industries, becoming an important component of the innovative information infrastructure in Anhui Province.

\section{Conclusion}

From the perspective of the current situation and development trend, the construction of CULRAS is heading for a fast track. After more than 20 years of development, all the economically developed provinces along the coast of China have established large-scale RA of UL. The basic pattern of interconnection and intercommunication in China's UL has been formed, and the idea of RS has also been unified. With the continuous development of China's social economy and higher education, as well as the rapid development of information technology, CULRAS' DR guarantee ability is becoming stronger and stronger, and the sharing, cooperation and exchange of resources among the member libraries of the alliances are also deepening, and "Knowledge Center", "Learning Center" and "Cloud Service Center" will be the important direction of the CULRAS development.

\section{Conflicts of Interest}

The author declares no conflicts of interest regarding the publication of this paper.

\section{References}

Cheng, J., \& Pei, L. (2008). On the Development Strategy of Digital Resources Consortium the Practice of Hubei University \& College Digital Libraries. Journal of Academic Libraries, 26, 34-37.

Hou, W. J., Gan, A. L., \& Liu, X. Q. (2017). Investigation and Analysis on Jiangxi Province Academic Digital Library (JADL) Construction. Journal of Academic Library and Information Science, 35, 124-126.

Li, C. Y., \& Duan, W. (2015). Discussion on the Development Strategies of Yunnan Academic Library Alliance. Journal of Library and Information Sciences in Agriculture, 27, 95-98.

Tan, L., \& Huang, N. (2019). Research on Co-Construction and Sharing of Digital Resources in Regional Library Alliance: Taking Hunan Academic Digital Library as an Example. New Century Library, 10, 46-53.

Tian, J., \& He, X. W. (2017). Discussion on the Practice of Construction of Local Literature Construction System based on Regional Library Alliance-Taking ZADL Local Literature Construction System as an Example. Library Science Research \& Work, 12, 29-32.

Wu, C. M., \& Zhou, Y. T. (2006). JALIS Influence on Digital Library Construction of 
University Libraries in Jiangsu Province. Library and Information Service, 50, 117-119.

Yan, L. (2009). The Investigation and Research on Digital Resource Construction of University Libraries in Anhui Province. Researches in Library Science, 6, 47-50.

Yang, F. L. et al. (2014). The Countermeasure Thinking about Developing Changbei Academic Library Alliance. Journal of East China Institute of Technology (Social Science), 33, 197-200.

Yi, L. (2014). Consideration on the Development of China's University Library Regional Consortiums: A Case of BALIS. Library Work in Colleges and Universities, 3, 53-55.

Yi, L. (2020). Research on the University Library Alliance of China. Open Access Library Journal, 7, e6672. https://doi.org/10.4236/oalib.1106672

Zhuang, Q. (2012). University Library Alliance in Yangtze River Delta. Research on Library \& Information Work of Shanghai Colleges \& University, 22, 4-12. 